\title{
Erratum
}

\section{Erratum: Bialecki et al., "Suppression of Presynaptic Glutamate Release by Postsynaptic Metabotropic NMDA Receptor Signalling to Pannexin-1"}

In the article, "Suppression of Presynaptic Glutamate Release by Postsynaptic Metabotropic NMDA Receptor Signalling to Pannexin1," by Jennifer Bialecki, Allison Werner, Nicholas L. Weilinger, Catharine M. Tucker, Haley A. Vecchiarelli, Jon Egaña, Juan Mendizabal-Zubiaga, Pedro Grandes, Matthew N. Hill, and Roger J. Thompson, which appeared on pages 729-742 of the January 22, 2020 issue, Figure $1 J$ appeared incorrectly. The curves of the cumulative interevent interval were mislabeled: "baseline" should be "with PPS" and vice versa. The online version has been corrected, and the updated Figure 1 appears below.

A

baseline $(\mathrm{t}=60 \mathrm{~s}) \quad \mathrm{t}=60 \mathrm{~s}$ ( $\mathrm{stim} \# 3)$

\section{B}
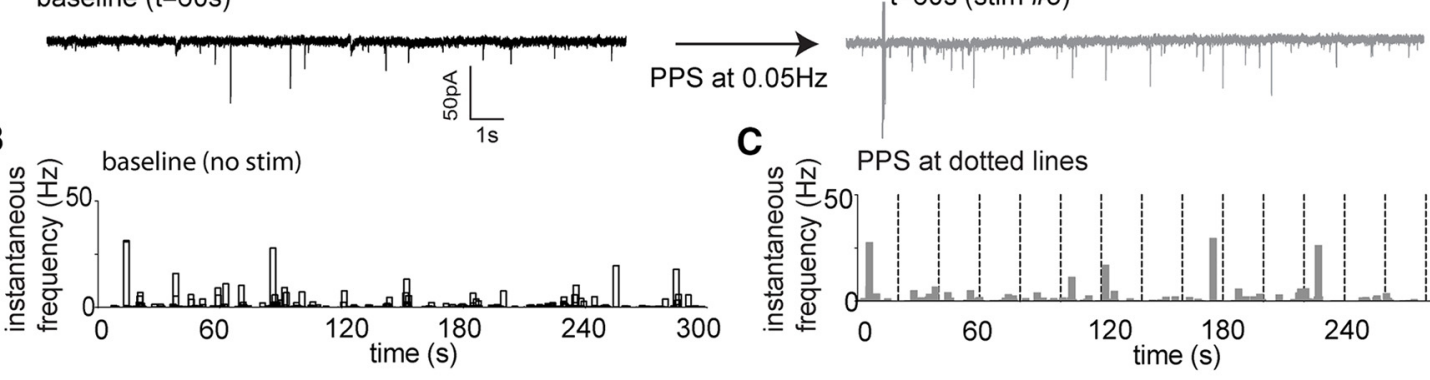

C. $\widehat{N}$ PPS at dotted lines

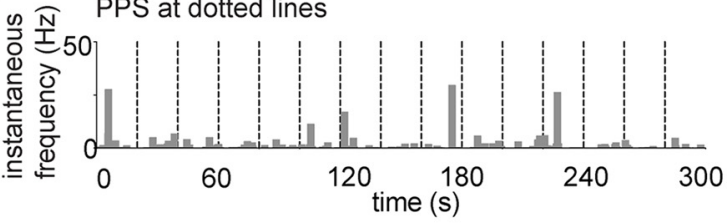

D



E



F

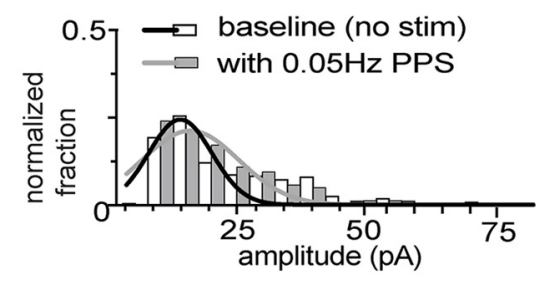

G

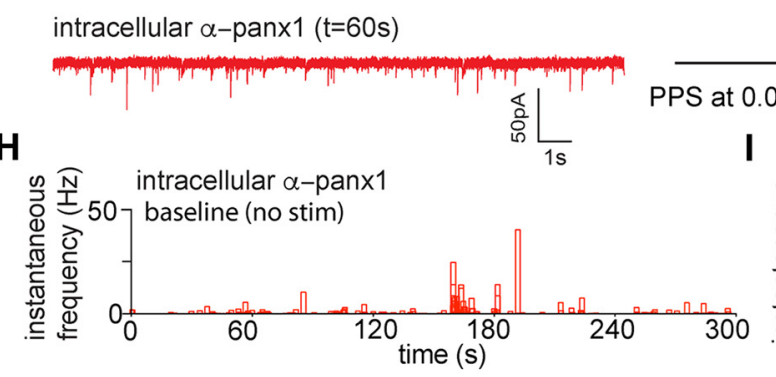

$t=60$ s (stim no. 3)



J

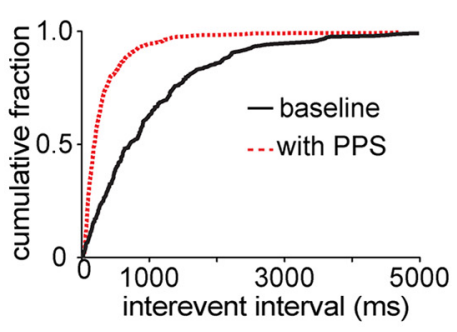

K

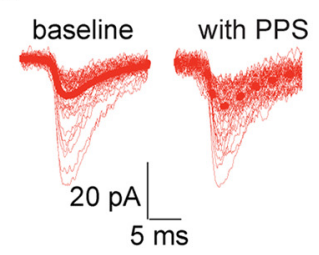

$\mathbf{L}$

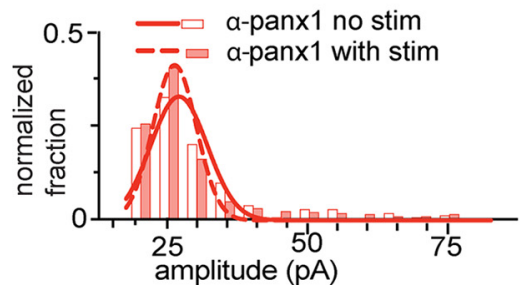

Figure 1. 